\title{
Creativity in liberal education before and after study commencement
}

\section{Van Goch, Merel}

Institute for Cultural Inquiry, Utrecht University, The Netherlands

\begin{abstract}
In today's society, creativity is an important quality. Creativity is defined as the ability to produce something novel and valuable as defined within a social context and it involves skills such as divergent thinking, problem solving and perspective taking. This study assesses the creative potential of students before and after commencement of an interdisciplinary, liberal undergraduate program. In between measurements, students followed a course in connective thinking through creative reading and writing. The results showed that students' creative potential developed over time. Implications for theory as well as practice are discussed.
\end{abstract}

Keywords: creativity; liberal education; interdisciplinarity; connective thinking; students 


\section{Introduction}

In today's society, creativity is an important, if not crucial, quality (Plucker, Beghetto, \& Dow, 2004; Sternberg, 2003). Creativity is considered a $21^{\text {st }}$ century skill, necessary to enter today's job market. Higher education institutions should thus map and foster students' creativity (Livingston, 2010), and research into how higher education institutions can map and foster students' creativity is needed (Kleiman, 2008; Plucker et al., 2004).

Here, creativity is defined as: "the interaction among aptitude, process, and environment by which an individual or group produces a perceptible product that is both novel and useful as defined within a social context" (Plucker et al., 2004). The social context that is referred to in this definition is higher education. Creativity is an integral part of the philosophy of liberal, interdisciplinary education. In liberal education, breadth and depth of study are combined, enabling students to encounter multiple perspectives and interpretations throughout diverse research fields. Indeed, students in an interdisciplinary undergraduate program find their education, themselves and interdisciplinarity inherently creative (Van der Lecq, 2016). Critical thinking, higher-order thinking skills, meta-cognitive reflection, problem-solving and analysis, are skills in which interdisciplinary students excel, compared to their peers (Haynes \& Brown Leonard, 2010). It is not clear, however, whether interdisciplinary studies create or attract creative students, or whether they do both. Therefore, the current study investigates the development of creativity of students before and after undergraduate study commencement.

Given the societal significance, it's important to gain insight into how creativity develops and can be stimulated in higher education. This study hypothesizes that students in interdisciplinary liberal education develop creativity through aspects of their interdisciplinary education, here, a course in connective thinking through creative reading and writing. The current study is part of a larger longitudinal study tracking several aspects of interdisciplinary students' development from before study commencement until after graduation. This substudy limits itself in time to students' development - from before study commencement, i.e., at orientation day, until the first semester, i.e., after the first course in connective thinking through creative reading and writing - and limits itself in design by only tracking students' creative development. The course teaches connective thinking through close-reading texts from multiple research fields that students have to connect with each other and with the course theme in their own essays. Students' age, sex and occupation at the time of their orientation in the program are related to creativity scores on two creativity tasks (Torrance, 1966; Urban \& Jellen, 1996). Note that although creativity is operationalized here as scores on two creativity tasks, the definition of creativity is much broader than just that (Plucker et al., 2004; Kleiman, 2008). 
Not only will insights in how creativity develops contribute to the scientific debate on the development of creativity and the impact of formal instruction (Plucker et al., 2004), it will also inform classroom teaching and hence benefit students.

\section{Methods}

\subsection{Participants, procedure and analysis}

All prospective students who were at the orientation days of a liberal arts and sciences program at a Dutch research university were invited to participate in the current study. This resulted in an initial sample of 299 students (mean age $=19$ years; 59\% female). At that time, $45 \%$ was enrolled in high school, $28 \%$ was taking a gap year, $19 \%$ was enrolled in higher education (16\% at a research university and $3 \%$ at a university for applied sciences). The other $8 \%$ either did something else or did not list an occupation. Of the 299 students participating at the first time of measurement, 230 students (77\%) enrolled in the program. At the second time of measurement, 181 students of the initial sample (79\%) were assessed again. In addition, 16 students who did not participate in any orientation day, but who were enrolled in the program at the time of the second measurement, were included in the study. Thus, in the end, this study could distinguish four groups of participants:

- students who were enrolled in the liberal arts and sciences program and who participated in both measurements (Group 1, 181 students),

- students who were enrolled in the program and only participated in the first measurement (Group 2, 51 students),

- students who participated in the first measurement but did not enroll in the program (Group 3, 67 students), and

- students who were enrolled in the program, who did not participate in the first measurement, but only participated in the second measurement (Group 4, 15 students).

Participants' creativity scores were first measured at the orientation days in the Spring before study commencement (Time 1), through two tasks. Students who did enroll in the program followed a course in connective thinking through creative reading and writing in the Fall of the academic year. The second time of measurement of this study took place in the last lecture of the connective thinking course (Time 2). Again, two tasks were administered. All tasks were administered plenary but individually, and anonymously. All data was scored independently by two research assistants; interrater reliability was high (> $95 \%)$.

The dependent variables in the analyses were the two creativity tasks at the two times of measurement. Independent variables included age, sex and occupation of the student groups. Additionally, the student groups themselves were considered independent variables. 


\subsection{Measurements}

\subsubsection{Torrance Test for Creative Thinking}

The Unusual Uses subtest of the standardized Torrance Test for Creative Thinking (TTCT; Torrance, 1966) was used to measure students' verbal divergent thinking. In the test, students were asked to elicit as many unusual uses of a common object as possible, within a given time frame (10 minutes). In one version of the test, cardboard boxes were the object (used at Time 1); in the other version, tin cans (used at Time 2). Answers were scored on three measures: fluency, flexibility and originality. These three subscores were combined into a total score, which was used for the analyses.

\subsubsection{Test for Creative Thinking - Drawing Production}

The standardized Test for Creative Thinking - Drawing Production (TCT-DP; Urban \& Jellen, 1996) was used to measure creative potential holistically. Students were provided with an incomplete drawing and were asked to finish it, in fifteen minutes. The incomplete drawing consists of a big square with several fragments in it, and one fragment outside the box. Two versions of this task exist: they are similar, but are mirror images of each other. Drawing productions were scored on fourteen different aspects, such as completions of the fragments, connections between the fragments, use of the fragment outside the box, humor and speed. These subscores were summed; the total score was used for the analyses.

\section{Results}

\subsection{Descriptives and correlations}

Descriptive statistics of the four different participant groups and the total sample can be found in Table 1. The occupation of students in Group 4 was not available. Relatively many students in Group 2 were enrolled in higher education and the average age of students in this group is higher than in other groups. Group 3 seems to entail relatively many students who visited the orientation days while still in high school and there were more women in this group than in any other group.

Before the main analyses, mean scores and correlation coefficients were calculated to inspect the data. The mean scores on both creativity tasks seemed to be higher at the second moment of measurement (Table 2). The correlation coefficients between the dependent variables show that, although ranging from weak to strong, all creativity scores were significantly correlated to each other (Table 3), even though the two creativity tasks measured different aspects of creativity, and even though different versions of the same tasks were used at the different moments of measurements. 


\subsection{Main analyses}

\subsubsection{Time 1}

Table 1. Descriptive statistics.

\begin{tabular}{cccccccc}
\hline & mean age & \% women & $\begin{array}{c}\% \\
\text { enrolled } \\
\text { in high } \\
\text { school at } \\
\text { Time 1 }\end{array}$ & $\begin{array}{c}\text { \% } \\
\text { enrolled } \\
\text { in higher } \\
\text { education } \\
\text { at Time 1 }\end{array}$ & $\begin{array}{c}\text { \% } \\
\text { taking a year } \\
\text { at Time } \\
\text { 1 }\end{array}$ & $\begin{array}{c}\text { enrolled } \\
\text { in the } \\
\text { program } \\
\text { at Time } \\
\mathbf{2 ?}\end{array}$ \\
\hline Group 1 & 181 & 18.88 & 60 & 45 & 18 & 33 & yes \\
Group 2 & 51 & 19.45 & 59 & 39 & 33 & 24 & yes \\
Group 3 & 67 & 18.66 & 75 & 58 & 16 & 25 & no \\
Group 4 & 16 & 20.56 & 63 & n/a & n/a & n/a & yes \\
Total & 315 & 19.01 & 63 & 45 & 19 & 28 & - \\
\hline
\end{tabular}

Table 2. Mean scores (and standard deviations) per participant group on both creativity tasks at both moments of measurement.

\begin{tabular}{ccccc}
\hline & Time 1 TTCT & Time 1 TCT-DP & Time 2 TTCT & Time 2 TCT-DP \\
\hline Group 1 & $43.18(16.249)$ & $32.71(10.875)$ & $54.67(23.871)$ & $37.92(11.155)$ \\
Group 2 & $47.85(19.298)$ & $33.74(12.040)$ & $\mathrm{n} / \mathrm{a}$ & $\mathrm{n} / \mathrm{a}$ \\
Group 3 & $41.67(16.740)$ & $33.39(10.992)$ & $\mathrm{n} / \mathrm{a}$ & $\mathrm{n} / \mathrm{a}$ \\
Group 4 & $\mathrm{n} / \mathrm{a}$ & $\mathrm{n} / \mathrm{a}$ & $47.56(19.586)$ & $37.00(10.777)$ \\
Total & $43.69(17.021)$ & $33.04(11.076)$ & $54.24(23.646)$ & $37.78(11.098)$ \\
\hline
\end{tabular}

Table 3. Correlations between dependent variables.

\begin{tabular}{lllll}
\hline & \multicolumn{1}{c}{ 1. } & 2. & 3. & $\mathbf{4 .}$ \\
\hline 1. Time 1 TTCT & - & & & \\
2. Time 1 TCT-DP & $.131^{*}$ & - & & \\
3. Time 2 TTCT & $.637 * *$ & $.187 *$ & - & \\
4. Time 2 TCT-DP & $.168 *$ & $.442 * *$ & $.189 *$ & - \\
\hline
\end{tabular}




$$
\text { Note. } *=\mathrm{p}<.05 ; * *=\mathrm{p}<.01
$$

TTCT. One-way ANOVAs were conducted to analyze the effects of age, sex and occupation on the TTCT scores. At Time 1, there were no statistically significant differences on the scores for students' age $(F(10,249)=.888, p>.05)$ or sex $(F(1,258)=$ $2.276, p>.05)$. Students' scores on the TTCT were statistically significant different for distinct occupations $(F(2,251)=31.98, p=.043)$. Students who were taking a gap year scored lower than students who were enrolled in secondary or higher education.

TCT-DP. With regards to the TCT-DP scores at Time 1, no effects of students' age $(F(10,283)=.801, p>.05)$ or $\operatorname{sex}(F(1,292)=.852, p>.05)$ were found. Again, students' occupation did have a significant effect on the creativity score $(F(2,285)=3.050, p=.049)$. However, in contrast to the results of the previous analysis, students who were enrolled in secondary education scored lower on this creativity test than students who were enrolled in higher education or who were taking a gap year.

Group comparisons. To investigate whether students who did and students who did not enroll in the program differed in terms of creativity scores, Groups 1 and 2 were compared to Group 3. An independent-samples t-test revealed that these groups did not differ significantly in terms of TTCT scores $(t(258)=1.058, p>.05)$ and TCT-DP scores $(t(292)$ $=.292, p>.05)$. This suggests that creativity scores and whether students enrolled are not related.

\subsubsection{Time 2}

TTCT. At Time 2, there were no effects of age $(F(9,175)=.793, p>.05)$, sex $(F(1,183)=$ $.100, p>.05)$ or occupation $(F(2,159)=.251, p>.05)$ on students' TTCT scores.

TCT-DP. Regarding TCT-DP scores at the second moment of measurement, there were no effects of age $(F(9,185)=.151, p>.05)$ or occupation $(F(2,169)=.031, p>.05)$. A statistical significant difference on TCT-DP scores was found for $\operatorname{sex}(F(1,193)=.6 .452, p$ $=.012)$ : women scored higher than men.

Group comparisons. Scores on both creativity tests were compared for Group 1 and Group 4. Group 1 participated in both times of measurements and hence filled out similar creativity tests twice, whereas Group 4 only participated in the second moment of measurement. An independent samples t-test showed that these groups did not score significantly differently on the TTCT $(t(183)=1.154, p>.05)$ and on the TCT-DP test $(t(193)=.294, p>.05)$. This seems to indicate an absence of a retest effect. 


\subsubsection{Development over time}

For Group 1, paired-samples t-tests were conducted to compare students' creativity scores over time. There was a significant difference in the scores on the TTCT at Time $1(\mathrm{M}=$ 42.92, $\mathrm{SD}=16.296)$ and at Time $2(\mathrm{M}=54.83, \mathrm{SD}=24.638 ; t(140)=7.44, p<.0001)$. There was also a significant difference in the scores on the TCT-DP at Time $1(\mathrm{M}=32.79$, $\mathrm{SD}=10.880)$ and at Time $2(\mathrm{M}=37.90, \mathrm{SD}=11.267 ; t(174)=5.79, p<.0001)$. These results suggest that students' creativity scores increased over time.

\section{Discussion}

This study investigated the development of students' creative potential before and after study commencement of an interdisciplinary undergraduate program. Before study commencement, age and sex did not influence creativity scores, but occupation did. After the connective thinking course, women showed greater creative potential on one creativity test than men. Furthermore, the results showed that students' creativity increased over time: after the course in connective thinking, students scored higher on creativity tasks. Whether students did or did not enroll after visiting the orientation day seemed not to be related to their creativity scores.

Students' occupation before study commencement was found to influence their scores. However, these results appear to be contradictory: on one test, students who were taking a gap year scored significantly lower, whereas on the other test, students who were in secondary education scored significantly lower than the other students. This may have to do with the nature of the administered tests. The test in which high school students scored lower focused on figural, holistic creative potential (Urban \& Jellen, 1996), and the test in which gap year students scored lower focused on verbal, divergent thinking creative potential (Torrance, 1966). Secondary education may focus more on factual knowledge teaching, explaining these results. A gap year, in which students either work, travel, or combine work and travel, may cause students to 'unlearn' more strict characteristics this test is scored on (. Future research should elaborate on these differences (Martin, 2010).

On one test, at one moment of measurement, women scored higher than men. Females have been shown to score higher than males on cognitive tasks more often. However, since there is much debate in the literature about these kind of sex differences (Miller \& Hapern, 2014; Stoet \& Geary, 2015), and since these sex differences did not occur across the board in this study, these results should be interpreted with caution and further research investigating these differences in-depth is necessary.

The improvement in creativity scores over time suggests that students' creative potential increased, possibly due to the connective thinking course that students took in between the two moments of measurements. In this course, students learned to find connections between 
seemingly unrelated insights and to look at topics from multiple perspectives. Students were trained to come up with multiple potential essay topics (divergent thinking) and then explore one topic in depth within one essay (convergent thinking). These convergent and divergent thinking skills were also tested in the creativity tests, thus, scores may reveal this progress (Van der Lecq, 2016; Haynes \& Brown Leonard, 2010). Alternatively, the mere fact that students were enrolled in higher education, or even, that they matured in the months between measurements, may have led to an increase in scores. The results seem not to be influenced by a retest effect: students who took the creativity tests for the second time (albeit a different version of the same test) did not score higher than students who took the tests for the first time.

In conclusion, the current results suggest that students' creativity develops over time. Future research should focus on collecting larger longitudinal datasets, to investigate exactly which aspects of higher education foster students' creativity, and whether interdisciplinary programs create or attract creative students, such that higher education institutions can educate students to become creative problem-solvers, ready to conquer today's job market.

\section{References}

Bull, K. S., Montgomery, D., \& Baloche, L. (1995). Teaching creativity at the college level: A synthesis of curricular components perceived as important by instructors. Creativity Research Journal, 8(1), 83-89.

Haynes, C., \& Leonard, J. B. (2010). From surprise parties to mapmaking: Undergraduate journeys toward interdisciplinary understanding. Journal of Higher Education, 81(5), 645-666.

Kleiman, P. (2008). Towards transformation: conceptions of creativity in higher education. Innovations in Education and Teaching International, 45(3), 209-217.

Livingston, L. (2010). Teaching creativity in higher education. Arts education policy review, 111(2), 59-62.

Martin, A. J. (2010). Should students have a gap year? Motivation and performance factors relevant to time out after completing school. Journal of Educational Psychology, $102(3), 561$.

Miller, D. I., \& Halpern, D. F. (2014). The new science of cognitive sex differences. Trends in Cognitive Sciences, 18(1), 37-45.

Plucker, J. A., Beghetto, R. A., \& Dow, G. T. (2004). Why isn't creativity more important to educational psychologists? Potentials, pitfalls, and future directions in creativity research. Educational Psychologist, 39(2), 83-96.

Sternberg, R. J. (2003). Wisdom, intelligence, and creativity synthesized. Cambridge University Press.

Stoet, G., \& Geary, D. C. (2015). Sex differences in academic achievement are not related to political, economic, or social equality. Intelligence, 48, 137-151. 
Torrance, E. P. (1966). The Torrance Tests of Creative Thinking. Princeton NJ: Personnel Press.

Urban, K. K., \& Jellen, H. G. (1996). Test for Creative Thinking - Drawing Production $(T C T-D P)$. Swets Test Services.

Van der Lecq, R. (20160. Self-authorship characteristics of learners in the context of an interdisciplinary curriculum. Evidence from reflections. Issues in Interdisciplinary Studies, 34, 79-108. 